Revue

Revue de l'histoire des religions

del'histoire des religions

$4 \mid 2012$

Varia

\title{
Guglielmo FORNI ROSA, Simone Weil politica e mistica
}

Turin, Rosenberg \& Sellier (« Dubbio e Speranza »), 2009, 144 p., $21 \mathrm{~cm}$, $13 €$, ISBN 978-88-7885-083-5.

\section{Silvia D'Intino}

\section{OpenEdition}

\section{Journals}

Édition électronique

URL : http://journals.openedition.org/rhr/8027

DOI : $10.4000 /$ rhr.8027

ISSN : 2105-2573

Éditeur

Armand Colin

Édition imprimée

Date de publication : 1 décembre 2012

Pagination : 569-571

ISBN : 978-2200-92796-7

ISSN : 0035-1423

\section{Référence électronique}

Silvia D'Intino, "Guglielmo forni Rosa, Simone Weil politica e mistica », Revue de I'histoire des religions [En ligne], 4 | 2012, mis en ligne le 24 janvier 2013, consulté le 22 septembre 2020. URL : http:// journals.openedition.org/rhr/8027 ; DOI : https://doi.org/10.4000/rhr.8027

Ce document a été généré automatiquement le 22 septembre 2020.

Tous droits réservés 


\section{Guglielmo FORNI ROSA, Simone Weil politica e mistica}

Turin, Rosenberg \& Sellier (« Dubbio e Speranza »), 2009, 144 p., $21 \mathrm{~cm}$, $13 €$, ISBN 978-88-7885-083-5.

\section{Silvia D'Intino}

\section{RÉFÉRENCE}

Guglielmo FORNI ROSA, Simone Weil politica e mistica, Turin, Rosenberg \& Sellier (« Dubbio e Speranza »), 2009, 144 p., $21 \mathrm{~cm}, 13 €$, ISBN 978-88-7885-083-5.

1 Cette deuxième édition, revue et augmentée, d'un recueil d'essais édité une première fois en 1996, couvre une décennie (1989-1999) de réflexions de l'auteur sur la pensée de S. Weil. L'incompréhension qui entoure aujourd'hui encore la philosophe est le point de départ du livre : «En général, on ne considère pas un aspect important de l'œuvre de Simone Weil, à savoir que ce n'est pas simplement une philosophie, mais une philosophie inspirée par la foi religieuse » (p.110). La nécessité de prendre en compte la dimension religieuse de la pensée de $\mathrm{S}$. Weil ne devient pourtant pas le moyen d'une lecture à clé : elle vise surtout à mieux cerner le parcours singulier de la philosophe dans son contexte historique.

2 Les deux premiers chapitres explorent son rapport à la pensée politique : Rousseau (ch. 1), la pensée marxiste et la pensée réactionnaire (ch. 2: «Le traditionalisme révolutionnaire »). S’y marque un engagement éthique comme épreuve de la vérité, qui aboutit à une pensée de l'homme au travail (ch. 3: "Sur la notion weilienne de la division du travail »). Si dans les premiers écrits la critique de la société trouvait dans le bien commun - la « volonté générale » rousseauiste - la possibilité d'une " harmonie » sociale, à partir de 1934, et notamment dans les Réflexions sur les causes de la liberté et de l'oppression sociale, seul l'individu apparaît à $\mathrm{S}$. Weil capable d'échapper à la machine sociale et à son irrationalité. La division du travail n'est plus regardée comme une forme de participation, mais comme une «spécialisation » prématurée de l'esprit, lui 
ôtant tout accès à la vérité et toute possibilité d'affranchissement. Le parallèle entre société et Église prolonge cette analyse pénétrante, où la mystique devient la voie d'accès privilégiée à la vérité, capable de soustraire l'individu aux mécanismes d'oppression - et qui se trouve développée dans les deux derniers chapitres.

3 Dans le chapitre 4 (" Hébraïsme et christianisme : la Lettre à un religieux ») G. F. utilise l'expression «christologie philosophique» pour indiquer la phase conclusive du parcours de $\mathrm{S}$. Weil et son point le plus avancé, entre l'idée d'un Christ cosmique, à l'échelle de l'univers, et celle de compassion - « un élément d'inspiration rousseauiste qui a été relu d'une manière originale par Simone Weil»(p.92). Si d'un côté, «l'affirmation morale ou religieuse [...] comporte que la condition sociale d'exclusion, de marginalité ou de malheur (Æđdipe, le Christ enseveli hors les murs comme un criminel) soit la position juste pour observer la réalité et connaître la vérité » (p. 13), de l'autre G. F. se dresse contre tout mysticisme de la douleur (mistica dolorista) à propos de S. Weil. La compassion est contre-nature (c'est là le point de divergence avec Rousseau); elle n'est pas spontanée. Elle demande une attention créatrice envers des créatures que la vie a jetées aux marges de l'existence, une attention qui les ramène à l'existence. C'est le sens qu'il faut donner à l'idée weilienne de "rédemption ", qui est inscrite, d'emblée, dans la Création même. La Lettre à un religieux explore les contradictions liées à la méconnaissance de ce nœud originaire : la vérité n'est pas le résultat d'une évolution (comme le veut l'orthodoxie catholique), ni ne surgit à un moment historiquement déterminé (comme le veut la Révélation hébraïque). Elle n'est pas plus une synthèse de vérités. Ce qui justifie le propos de $\mathrm{S}$. Weil selon lequel " chaque religion - pour qui y adhère entièrement - est l'unique vraie » (Cahiers I, cité p. 105).

4 Tout en reconnaissant des pages et des livres entiers de vérité dans l'Ancien Testament, S. Weil refuse donc l'idée d'une révélation hébraïque : c'est le cœur de sa critique du judaïsme. Celle du christianisme se concentre sur l'union à l'Église: dans le catholicisme, l'individu est pris à nouveau dans une "masse » et perd sa faculté de jugement. Une telle critique, rappelle G. F., s'explique notamment par les circonstances historiques - l'entre-deux-guerres - qui ont conduit S. Weil à se méfier de tout phénomène de mécanisation et massification.

5 Aussi aboutit-on à la nécessité d'une «nouvelle christologie» (ch.5), très loin cependant de la christologie spéculative, à la même époque, d'un Blondel ou d'un Teilhard. La figure du Christ, chez S. Weil, s'éloigne profondément de celle consignée par l'orthodoxie ecclésiastique, où domine «la distinction [...] entre vérité au sens spéculatif, ou cognitif, et vérité au sens pratique, distinction qui se retrouve aujourd'hui encore dans les documents du magistère catholique » (p. 107). Un nouveau modèle, plus radical, du rapport à la transcendance permet à $S$. Weil d'éviter tout intellectualisme : «Or, la présence de cet élément, de cette radicalité, transforme la christologie weilienne en une ontologie existentielle, en conflit avec le sens dominant de la modernité, et surtout, avec le sens du christianisme comme phénomène culturel particulier, interne à la modernité » (p. 111). Au cœur de sa christologie se trouve le concept de décréation : acte de pure obéissance qui est aussi la part de liberté réservée à l'homme, un contact avec la vérité, toujours « attendue » et trouvée, jamais produite. Mais pourquoi faudrait-il voir ici, avec G. F., une tendance anti-philosophique? « Il y a sans aucun doute ici une tendance anti-philosophique: la vérité, nous l'attendons; nous ne la cherchons pas, ne la fabriquons pas » (p. 115). Cette attitude vis-à-vis de la 
vérité, n'est-ce pas au contraire le propre de la philosophie ? Ne peut-on considérer que «la principale illusion consiste à penser que la vérité est le résultat ultime d'un processus de pensée ", comme l'écrivait Hanna Arendt à Mary McCarty (lettre du 20 août 1954) ? «La vérité », poursuit-elle, « est toujours le début de la pensée ; penser en soi reste toujours sans résultat. C'est ce qui fait la différence entre la "philosophie » et la science. La science a des résultats, la philosophie jamais. L'acte de penser commence après qu'une expérience de vérité a fait mouche, si l'on peut dire.

6 Le volume est complété par un petit glossaire des notions clés de la philosophie weilienne, avec leur émergence dans l'œuvre de la philosophe et leur contexte d'emploi.

\section{AUTEURS}

\section{SILVIA D'INTINO}

Centre national de la recherche scientifique,

Anthropologie et histoire des mondes antiques. 